\title{
Study on Very high-cycle Bending Vibration Fatigue Performance of TC17 Titanium Alloys under Corrosion and Laser Shock Processing
}

\author{
Hui Zhang ${ }^{1}$, Xuan Chen ${ }^{2}$, Quantong Li $^{1}$, Li Cheng${ }^{1}$, Jingsheng Shen ${ }^{1}$, Wenbin Cui ${ }^{1}$, and \\ Changkai Wang ${ }^{1}$
}

${ }^{1}$ Air Force Engineering University

${ }^{2}$ Affiliation not available

June 24, 2020

\begin{abstract}
In this paper, the very high-cycle fatigue performance of TC17 titanium alloys under corrosion environment and laser shock was studied by the load of first-order bending vibration. The results show that the very high cycle fatigue performance of TC17 titanium alloys has no fatigue limit in the traditional sense and different surface processing has different effects on the very high cycle fatigue properties of TC17 titanium alloys. The very high cycle fatigue performance of TC17 under corrosion environment did not decrease significantly, but the very high cycle fatigue performance of TC17 strengthened by laser shock treatment could be greatly improved. With the SEM analysis, it was found that the specimen crack initiation showed two modes: surface and sub-surface, which was independent of the internal inclusions and defects. No sign of internal crack initiation was found and the sub-surface crack propagation did not show "fish-eye".
\end{abstract}

Study on Very high-cycle Bending Vibration Fatigue Performance of TC17 Titanium Alloys under Corrosion and Laser Shock Processing

Hui Zhang ${ }^{1} \mid$ Xuan Chen ${ }^{1} \mid$ Quantong Li $^{1} \mid$ Li Cheng$^{1} \mid$ Jingsheng Shen ${ }^{1}$

Wenbin Cui ${ }^{1}$ | Changkai Wang ${ }^{1}$

${ }^{1}$ Aeronautics Engineering College, Air Force Engineering University

Correspondence :

Xuan Chen

Aeronautics Engineering College, Air Force Engineering University, Xi'an, Shaanxi Province 710038, PR China

Email address: chenxuan186@gmail.com

Abstract:In this paper, the very high-cycle fatigue performance of TC17 titanium alloys under corrosion environment and laser shock was studied by the load of first-order bending vibration. The results show that the very high-cycle fatigue performance of TC17 titanium alloys has no fatigue limit in the traditional sense and different surface processing has different effects on the very high-cycle fatigue properties of TC17 titanium alloys. The very high-cycle fatigue performance of TC17 under corrosion environment did not decrease significantly, but the very high-cycle fatigue performance of TC17 strengthened by laser shock treatment could be greatly improved. With the SEM analysis, it was found that the specimen crack initiation showed two modes: surface and sub-surface, which was independent of the internal inclusions and defects. No sign of internal crack initiation was found and the sub-surface crack propagation did not show "fish-eye". 
Keyword: Very high-cycle fatigue; Titanium alloy; Surface crack; Subsurface crack

\section{1 | INTRODUCTION}

With the continuous improvement of aero-engine technology, the requirements for the engine service life also keeps increasing. Taking compressor blades as an example, if the vibration frequency is $2.8 \mathrm{KHz}$ and the service life is over 2,000 hours, then the number of repeated loads on the blades will reach $0.6 \times 2000 \times 2800 \times 3600=1.2 \times 10^{10}$ cycles. And the high-order resonance of the engine's working blade is easy to reach this frequency. The number of cycles of gas turbine engine components can reach up to $10^{10}$ to $10^{11}$. Pointed out by professor C. Bathias in his works ${ }^{1}$. This means that the blades are prone to cracks the blade break or even the blade failure. The falling metal block will damage the compressor rotator and the stator vane at the back, resulting in a second accident, and severe damage to the engine. Therefore, this type of damage is called "very high-cycle fatigue failure ${ }^{2}$." It is not only one of main damage forms of aero-engine blade, but also one of aviation technical problems recognized by countries across the world.

In view of the severe problem, countries worldwide have conducted extensive research on the very high-cycle fatigue problem ${ }^{3-11}$. Up to now, two loading methods have been adopted in the study on very high-cycle fatigue testing technology: axial tension and compression ${ }^{12-14}$ and rotating bending ${ }^{15-17}$, where the specimens are mostly round bar or flake-shaped ${ }^{18}$. In addition, some researchers have conducted studies upon method of either the three-point bending fatigue loading ${ }^{19}$ or the four-point bending fatigue loading ${ }^{20}$. However, it is undeniable that the stress state of specimen, under the test methods, is different from that of real aviation engine blades, thus it is hard to accurately simulate and estimate the fatigue life of the components. Individual researchers of perseverance may use a shaker on very high-cycle fatigue testing ${ }^{21}$. After all, this method can truly be used to examine the stress state of real aero-engine blades. Once the method is used, it will cost the researchers more samples, money and time. But time is bigger problem than money is in this case. Therefore, it is necessary to try alternative methods to conduct studies.

During the operation of aviation engines, the main form of blades failure is fracture failure caused by bending vibration fatigue, which means, the blades are subject to alternating bending stress, under extremely high centrifugal load. Among all the fracture failures of the blades caused by bending vibrations, the first-order bending vibration is the most common and of the greatest dangers. Therefore, the vibration of aero-engine compressor blades could be simplified to the first-order bending vibration under the blade-base flutter load and aerodynamic load.

Based on this idea, the paper takes advantage of a new loading form to conduct research on very high-cycle fatigue characteristics of TC17 titanium alloys used in aviation engine blades and explores the mechanical properties of the TC17 titanium alloy specimen under corrosion environment and laser shock.

\section{2 | EXPERIMENTAL PREPARATIONS}

\section{1 | Experimental System}

In the light of the first-order bending vibration of blades, the test adopted the fatigue loading mode of asymmetric bending vibration. The test system mainly includes ultrasonic frequency generator, transducer, displacement amplifier, sample, test control system (computer control system and laser displacement sensor) and cooling system.

In this test system, the ultrasonic frequency generator converted the AC signals of $50 \mathrm{~Hz}$ into electrical signals of $20 \mathrm{kHz}$. When the piezo-ceramic transducer received such electrical signals, it transformed them into mechanical vibrations of $20 \mathrm{kHz}$ in the axial direction. Then after the vibration amplitude was enlarged by the displacement amplifier, it was loaded to the fixed end of the specimen to stimulate their base vibrations. At this time, one end of the specimen was subjected to harmonic excitation while the other vibrated freely. As a result, the specimen generated the bending vibrations similar to the very high-cycle bending vibrations of cantilever beam.

This mode of excitation resembled the bending vibration of blades as was excited by the low-frequency 
magneto-electric shaker. In the course of the test, the first-order symmetrical bending resonance of the specimen could be achieved through adjustment of the excitation frequency and moreover, different value of stress amplitudes could also be obtained by controlling the displacement amplitude of the end of specimen.

\section{2 | Materials and Specimen}

The TC17 specimen used in this paper is a type of $\alpha+\beta$-type titanium alloy rich in $\beta$ phases, with advantages in terms of high strength, good fracture toughness, high hardenability and wide forging temperature range ${ }^{22}$. It can meet the requirements of damage tolerance design, and that of high structural benefits, high reliability as well as low manufacturing cost. It is especially suitable for manufacturing aviation engine compressor disks and blades. The main chemical composition (wt\%) is shown in Table 1, the total amount of other elements is equal or less than 0.3 , and the content of single element is not more than 0.1 . The heat treatment process is double quenching heat treatment: $800^{\circ} \mathrm{C} \times$ four hours with water cooling and $600^{\circ} \mathrm{C} \times$ eight hours with air cooling.

TABLE 1 Chemical composition (wt\%) of TC17

\begin{tabular}{llllllll}
\hline $\mathrm{Al}$ & $\mathrm{Cr}$ & $\mathrm{Zr}$ & $\mathrm{Mo}$ & $\mathrm{Sn}$ & $\mathrm{C}$ & $\mathrm{O}$ & $\mathrm{Ti}$ \\
$4.50^{\sim} 5.50$ & $3.50^{\sim} 4.50$ & $1.60^{\sim} 2.40$ & $3.50^{\sim} 4.50$ & $1.60^{\sim} 2.40$ & $<=0.05$ & $0.08^{\sim} 0.13$ & Based \\
\hline
\end{tabular}

The dimensions of the bending vibration fatigue specimen designed in this paper are shown in Figure 1 and the dimensions are: $\mathrm{L}_{1}=10 \mathrm{~mm}, \mathrm{~L}_{2}=10 \mathrm{~mm}, \mathrm{~L}_{3}=5 \mathrm{~mm}, \mathrm{~L}_{4}=3.2 \mathrm{~mm}, \mathrm{R}_{1}=3 \mathrm{~mm}, \mathrm{R}_{2}=1 \mathrm{~mm}, \mathrm{~h}=3 \mathrm{~mm}$ and $\mathrm{b}=10 \mathrm{~mm}$. Meanwhile, to avoid obvious stress concentration, a semi-circle groove is set at the free end and the maximum stress area is moved to that end.

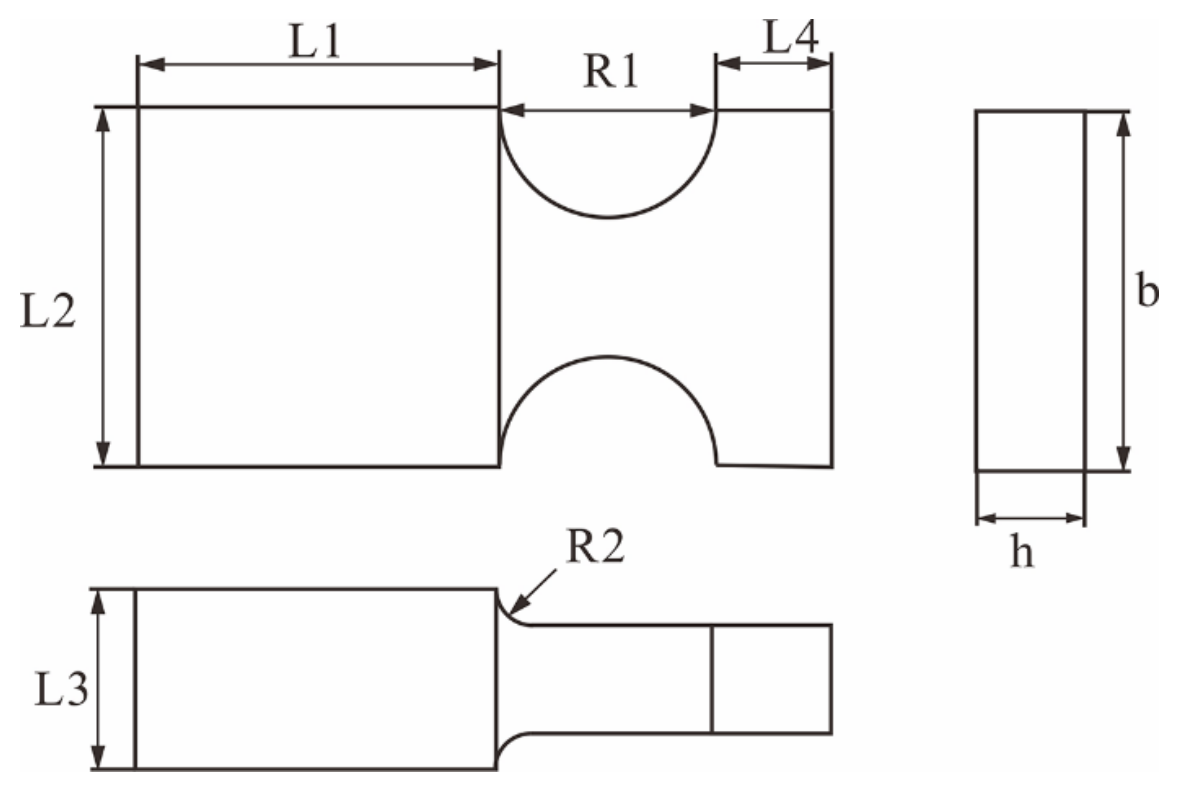

FIGURE 1 Diagram of specimen dimensions

As shown in Figure 2, the relationship curve between the radial amplitude and the maximum stress of the specimen is shown through harmonic response analysis. It is found from the figure that, when the specimen vibrates, the displacement of the middle section of arc is the smallest and that of the end is the largest. While the stress at the middle section of the arc center is the largest and attenuates quickly towards both ends, and the tress at the end is the smallest. 


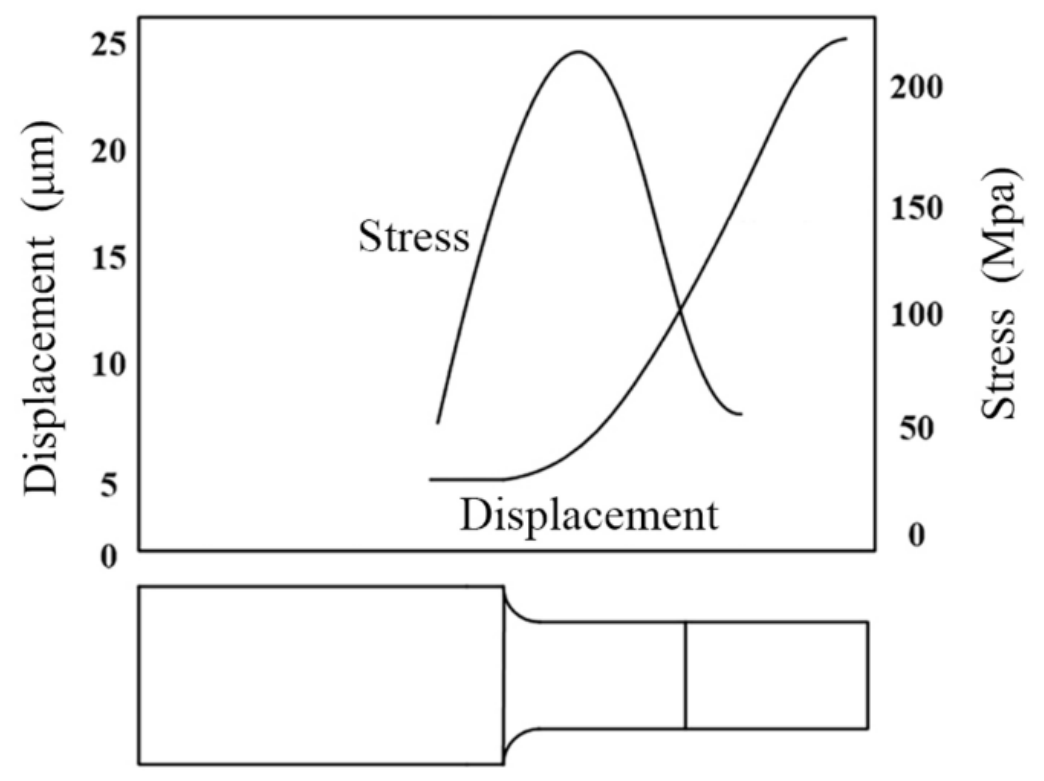

FIGURE 2 Diagram of specimen axial displacement and stress distribution

Based on analog computation by ANSYS finite element software, the result shows that the specimen dimensions have met the resonant conditions of $20 \mathrm{kHz}$ (error within $0.5 \mathrm{kHz}$ ) transverse bending vibration. The ultrasonic fatigue test technology can be used to conduct ultrasonic-cycle fatigue test with first-order bending of the designed specimen. Figure 3 presents the stress distribution of the specimen.

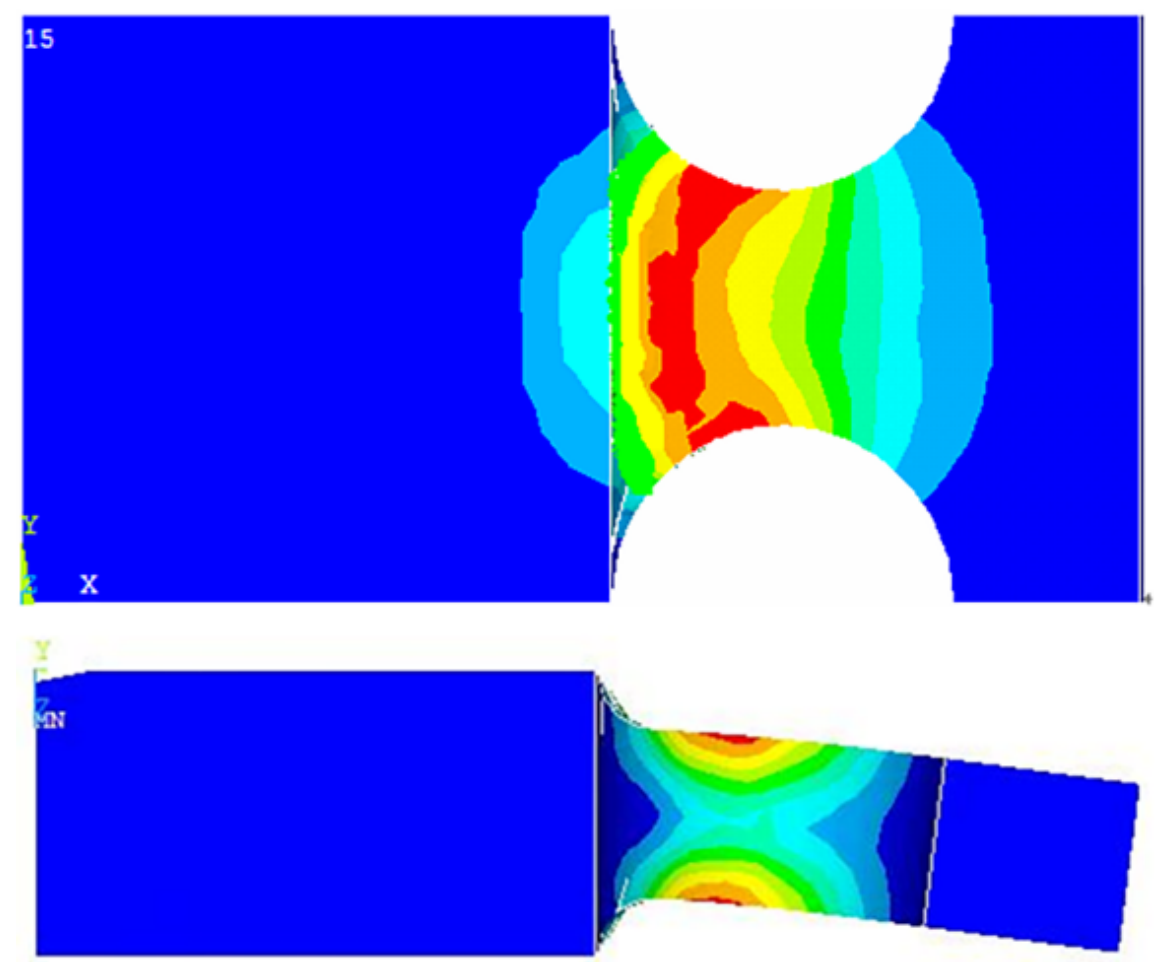


FIGURE 3 Diagram of specimen stress distribution

It can be seen from Figure 3 that, the maximum stress area is not in contact with the transition arc and is roughly distributed in the semi-circular groove. The maximum stress area is relatively ideal and conducive to processing and corrosion treatment in this area in the subsequent tests. At the same time, metallographic sandpaper is used to grind and polish the test section to eliminate the effect of surface processing defects. The surface roughness is $\mathrm{Ra}=0.32 \sim 0.64 \mu \mathrm{m}$, which meets the requirements of surface finish for specimen.

\section{3 | Corrosion Test}

The accelerated corrosion test has been carried out in ZJF-75 cyclic immersion corrosion High-Low Temperature-Humidity Test Chamber. The humidity range is $(95 \pm 5) \%$, the temperature control precision is $\pm 2^{\circ} \mathrm{C}$, and the humidity control precision is $\pm 3 \%$.

Before the accelerated corrosion test, the specimen surface has been cleansed with absolute ethanol, then cleansed with deionized water and dried.

The accelerated corrosion test has lasted for 720 hours. The corrosion of specimen has been observed and recorded during the test, and the specimen has been cleaned with deionized water and dried after the test.

\section{4 | Laser Shock Processing}

The laser shock processing has been completed on the laser shock processing system. The system consists of three parts: high-power pulse laser, workpiece clamping motion platform and related control and monitor system. Among them, the selected laser is a SGR-25 high-energy Nd: YAG laser. This type of laser has the feature of high power, rich repetition rate, high stability, and high beam quality and so on. The equipment can meet the need of the laser shock processing of materials, such as aluminum alloys, stainless steel, alloy steel, titanium alloys and nickel-based superalloys, as well as the most of engine parts. The workpiece clamping motion platform uses a high-precision five-degree-of-freedom frame robot, which adopts electromechanical optical-hydraulic multi-device integrated control, impact path planning, precise control and laser beam scanning control, with high precision and quick response. The real-time monitoring system can watch over laser energy emitted by the laser and motion status of the workpiece, and will initiate warnings against abnormalities. The automatic shock processing can be completed by using prepared software to coordinate the motion of robot and emission of the laser pulse through the control system. In the outer optical system, reflected light and optical path pollution are adopted to prohibit the conversion of round light spots into square light spots in the two-sided offset optical path.

In this test, the main parameter of laser shock processing is wave length of $1064 \mathrm{~nm}$. Although the energy parameter of laser provides a range of values, and the parameters are nominally continuous, it's hard for the specimen to go through shock processing under all the values. Based on the theoretical calculation result of power density combined with conclusions in the existing researches and the operation of the companies as well as experience of researchers, the energy can be optional, being either 4 or $7.5 \mathrm{~J}$. The absorption protection layer is black tape, and the diameter of light spot is $3 \mathrm{~mm}$ and $4 \mathrm{~mm}$. A repeated shock with the power density of $4 \mathrm{GW} / \mathrm{cm}^{2}$ is applied on the specimen for one time. Laser shock processing has been performed on 50 chosen specimens in the test, with parameters shown in Table 2.

TABLE 2 Parameters of specimen laser shock processing

\begin{tabular}{lllll}
\hline Specimen No. & Wave Length $(\mathrm{nm})$ & Energy $(\mathrm{J})$ & $\begin{array}{l}\text { Light Spot } \\
\text { Diameter }(\mathrm{mm})\end{array}$ & $\begin{array}{l}\text { Power Density } \\
\left(\mathrm{GW} / \mathrm{cm}^{2}\right)\end{array}$ \\
1 to 50 & 1064 & 7.5 & 4 & 4 \\
\hline
\end{tabular}

\section{3 | RESULT AND DISCUSSION}

The TC17 titanium alloy specimens have been divided into three groups, where the first group has remained in original state, the second group has undergone pre-corrosion processing and the third group has received 
laser shock processing. The number of constant amplitude fatigue specimens in each group is 25. Very high-cycle fatigue test has been then after conducted on these three groups of specimens.

\section{1 | The Result of Accelerated Corrosion test}

The surface status images of the specimens have been obtained, under the JSM-6360 electronic microscope metallographic analyzer, where the specimens have been analyzed before and after the accelerated corrosion test. The surface status images of the unprocessed specimens are shown in Figure 4(a), and that of the pre-corroded are shown in Figure 4(b).

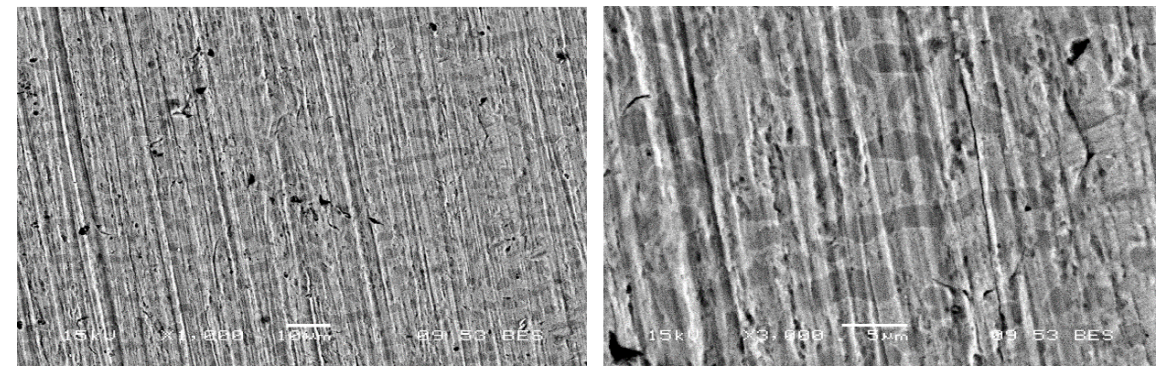

FIGURE 4 (a)The surface status of the unprocessed specimens and (b) that of the pre-corroded

By comparing the data in Figure 4, it can be seen that the surface status of the unprocessed is not obviously different from that of the pre-corroded specimens. It can also be found that there are tiny $\alpha$ phase mass points on the background of the tissue of $\beta$ substrate while $\alpha$ phases are majorly distributed on $\beta$ phase in the shapes of lath and needle. However, no obvious pitting or etch pits have been found.

In order to further examine the corrosion degree on specimen surface,tissue composition analysis has been conducted. Three analysis points have been randomly selected on the specimen surfaces for chemical composition analysis. The selected analysis points are shown in Figure 5, and the chemical composition at points 1, 2 and 3 is shown in Figure 6(a), Figure 6(b) and Figure 6(c) respectively. 


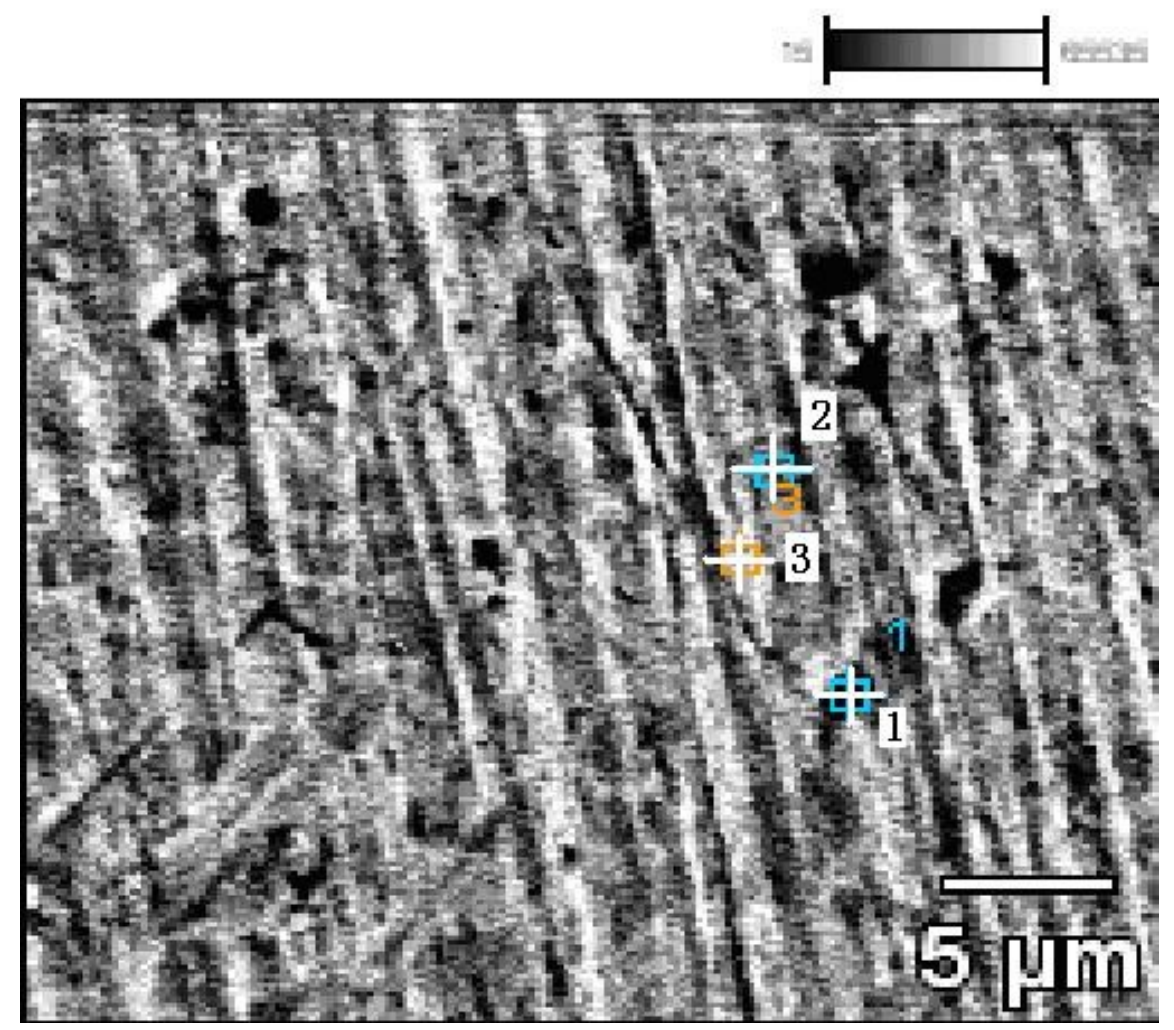

FIGURE 5 Selected points for specimen surface chemical composition

Table 3 shows the weight percentages of chemical composition on the surface of the corroded specimens.

TABLE 3 Weight percentages of chemical components of corroded specimen surfaces

\begin{tabular}{lllllll}
\hline & $\mathrm{C}$ & $\mathrm{O}$ & $\mathrm{Al}$ & $\mathrm{S}$ & $\mathrm{Ti}$ & $\mathrm{Cr}$ \\
Base_pt1 & 4.72 & 28.90 & 16.82 & - & 49.57 & - \\
Base_pt2 & 7.06 & - & 5.02 & - & 87.92 & - \\
Base_pt3 & 7.14 & - & 3.23 & 2.15 & 80.07 & 7.42 \\
\hline
\end{tabular}



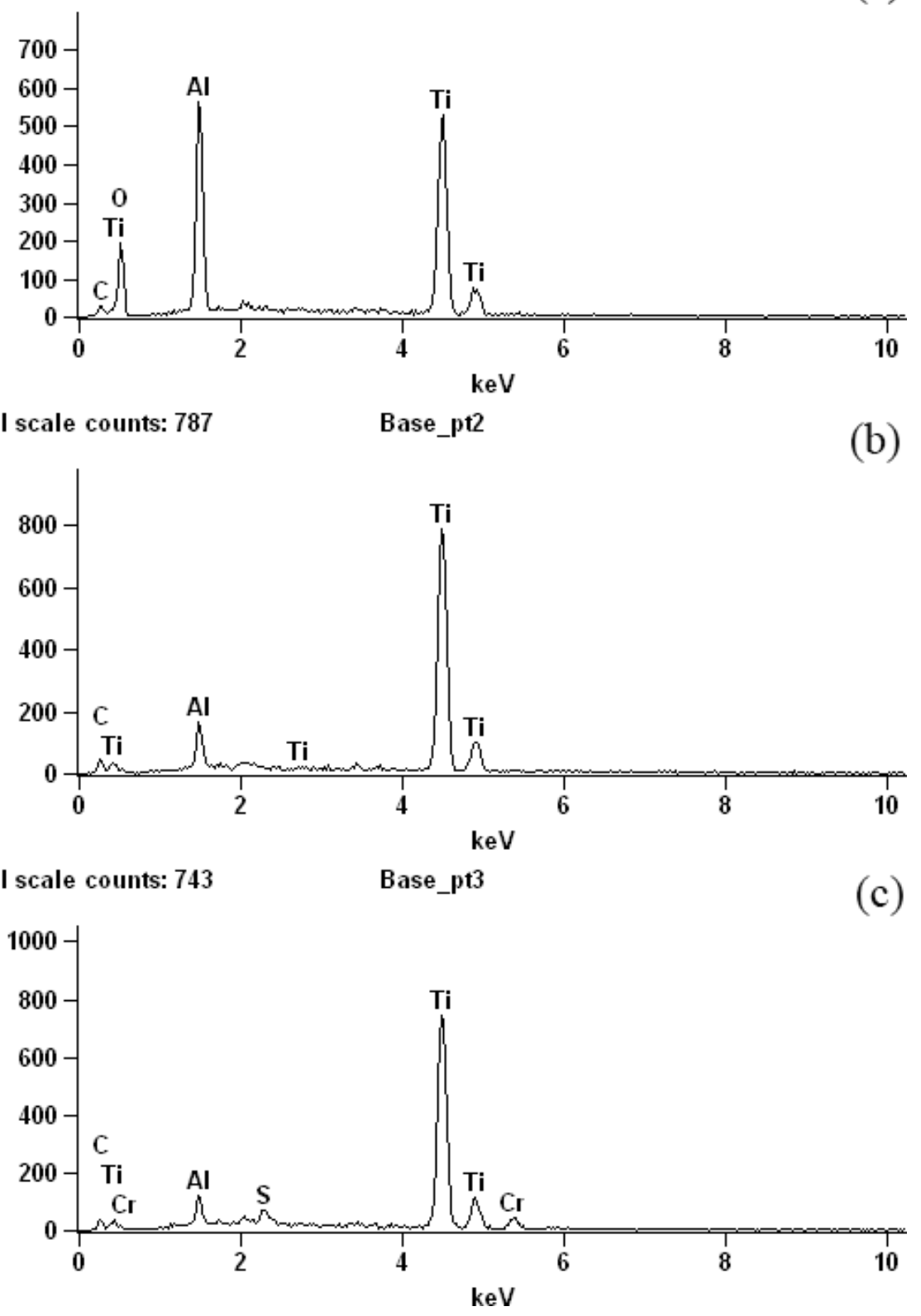

FIGURE 6 The chemical composition at points 1(a), 2(b) and 3(c)

By analyzing the chemical composition at points 1, 2 and 3 shown in Figure 6, and comparing Table 3 with Table 1, it is found that, the $\mathrm{C}$ (carbon) content in the tissue components on the surface of corroded specimen are generally increasing, while the $\mathrm{O}$ (oxygen) content greatly decreases at points 2 and 3, indicating that , corrosive pitting has been formed at these two points and the surface oxide film $\left(\mathrm{TiO}_{2}\right)$ has been damaged. At point 3, the $\mathrm{Al}$ (aluminum) content has decreased significantly, but there is a relative increase of the contents of $\mathrm{S}$ (sulfur) and substrate material $\mathrm{Ti}$ (titanium), which indicates that, the Al (aluminum) in the alloy is relatively easy to be corroded, while $\mathrm{Ti}$ (titanium) is relatively stable, and thus the Al (aluminum)content in the alloy substrate at this point decreases and the products of corrosion containing $\mathrm{S}$ (sulfur) and Ti(titanium) are formed. 


\section{2 | Result of Laser Shock Processing Test}

A SEM has been used to observe the surface of the specimen before and after laser shock processing. The result shows that there is an obvious deepened color strip on the surface of the specimen after laser shock processing. When the power density reaches $4 \mathrm{GW} / \mathrm{cm}^{2}$, the depth becomes about $120 \mu \mathrm{m}$, as shown in Figure 7 .

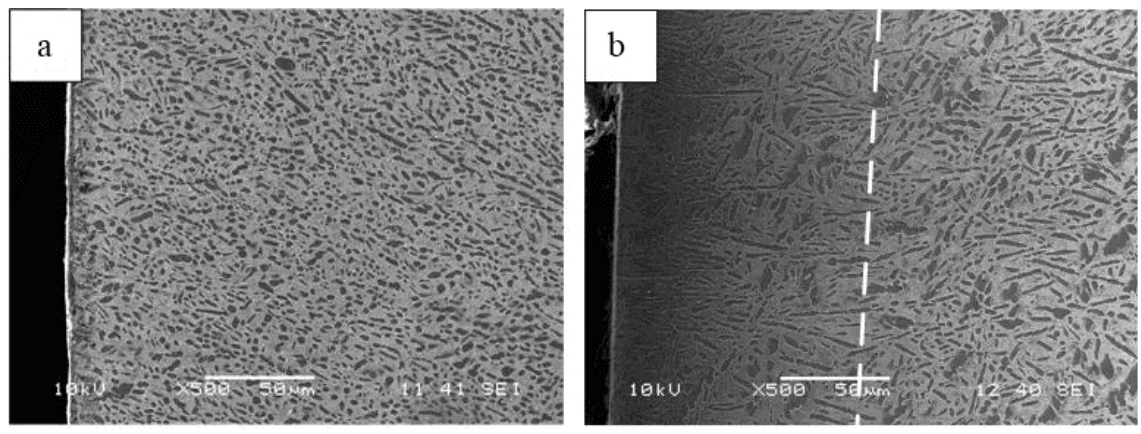

FIGURE 7 SEM images of the cross-section before (a) and after (b) the shock

It can be seen that laser shock processing has an effect on the surface of the TC17 titanium alloy and the color of the cross-section gradually changes from darker in the affected area to lighter in the substrate.

A Proto-LXRD X-ray diffractometer has been used to perform the residual stress test for the processed TC17 titanium alloy specimens, among which, the specification is about $20 \times 25 \times 6 \mathrm{~mm}$.

As the electrochemical corrosion of titanium alloy may generate etch pits, the specimens are gradually delaminated and thinned time-by-time by the chemical corrosion method, (the corrosive solution is prepared based on the following volume percentages: $\mathrm{HNO}_{3}(24 \%)+\mathrm{HF}(14 \%)+\mathrm{H}_{2} \mathrm{O}(62 \%)$ ), at a corrosive rate of $0.2-0.5 \mu \mathrm{m} / \mathrm{s}$ per $1 \mathrm{~cm}^{2}$, to complete the test of a residual stress along the depth direction after the laser shock processing. When measuring the relaxation effect of the temperature on the residual stress produced by laser shock processing, due to limitations such as the technical equipment, the residual stress test cannot be conducted the same time with heat preservation. The specimens are taken out after being kept in the incubator for a certain time, and then put back for heat preservation. The heat preservation and test process keep on repeated until the result of residual stress no longer changes obviously.

The laser shock processing technique uses the force effect of high-pressure plasma impact waves produced by the high-power pulse laser irradiating metal surfaces to change the microstructure of the surface materials and retain the residual stress on the deeper thickness in order to prolong the fatigue service life of the materials. The improvement of fatigue resistance of the materials mainly depends on the residual stress generated by laser shock processing. The surface residual stress can not only prevent fatigue crack initiation but also increase the crack closure effect to reduce the expansion rate of short fatigue cracks. In this paper, $\mathrm{X}$-ray diffractometer is used to measure the residual stress along the depth direction of the TC17 material specimens after laser shock processing with different power densities and for different times.

The distribution of residual stress along the depth direction after shock under the power density of $4 \mathrm{GW} / \mathrm{cm}^{2}$ is shown in Figure 8. It can be seen from the figure that the residual stress, after the laser shock processing, becomes the highest on the surface, and the amplitude of the residual stress is increasing at a smaller margin along with the depth. The gradient of the residual stress was relatively larger when the depth is before $200 \mu \mathrm{m}$. The residual stress is still around $-100 \mathrm{MPa}$ when the depth reaches about $500 \mu \mathrm{m}$. From the experimental experience, it's known that when the power density reaches about $4 \mathrm{GW} / \mathrm{cm}^{2}$, the surface residual stress climbs the highest, that is, $-530.4 \mathrm{MPa}$. 


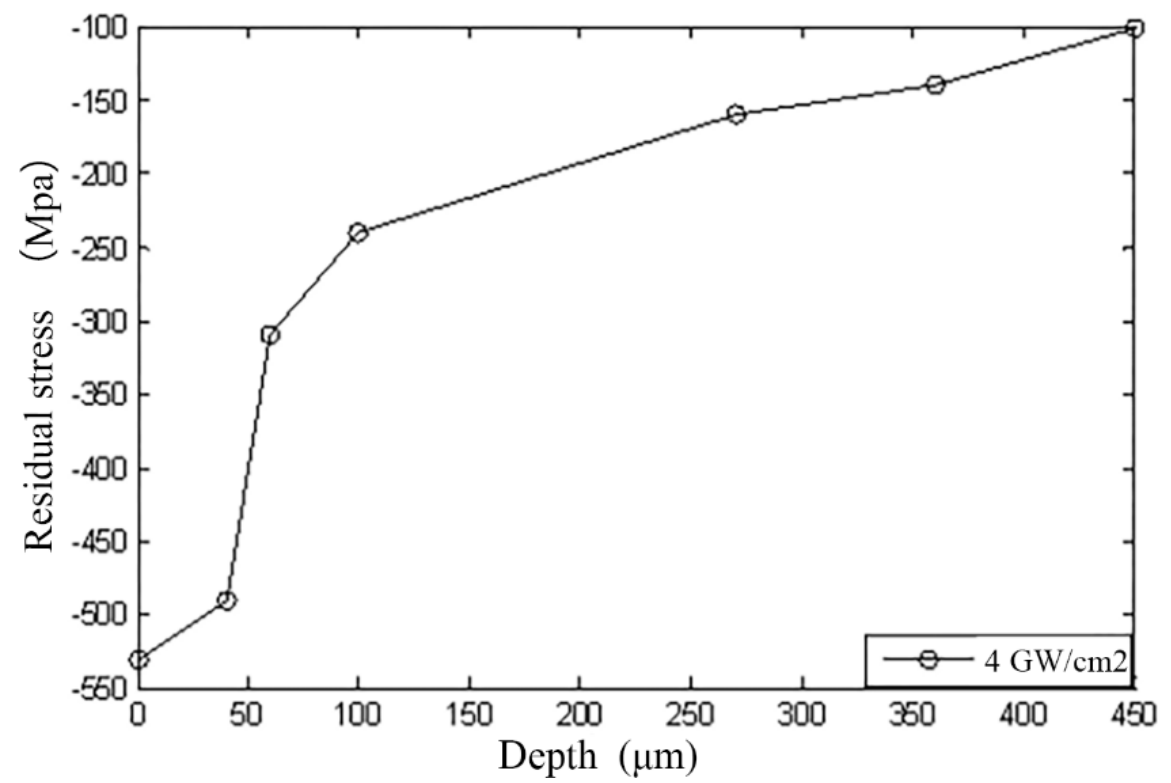

FIGURE 8 Residual stress distribution along the depth direction

From the above-mentioned test results, it can be found that there are residual stress fields on the surfaces after the laser shock processing. The residual stress results from the heterogeneity of plastic deformation and the elastic recovery effect of the non-plastic deformation. In the process of the laser shock processing, due to the plasma shock waves generated by laser irradiation, the force effect of the shock waves causes plastic deformation within a certain depth of the surface layer of the material, and the residual stress is formed in the impact area due to the uneven plastic deformation between the surface and the internal layer. It can be inferred that the internal stress of the material is tensile, subject to the stress balance principle.

\section{3 | Result of Very high-cycle Fatigue Test}

In this paper, the system loading and data collection of ultrasonic fatigue test, are all achieved with the control software. In order to accurately monitor the amplitudes of the cyclic load, the vibration displacement of the ultrasonic fatigue system has been calibrated before conducting the test. The system no longer meets the resonance conditions and the fatigue test system stops automatically when the fatigue cracks occur under cyclic loading.

In the very high-cycle test, the specimens resonate and temperature rises due to the absorption of ultrasonic vibration energy and internal friction. Therefore, the air cooling method is adopted during the test to keep the temperature of the specimen surface equal with room temperature. During the test, firstly, the specimens are fixed on the displacement amplifier with screws and are excited by external signals to produce resonance. In this way, the specimens are bent and deformed under excitation of external signals.

The ultrasonic fatigue test on the specimens at $20 \mathrm{kHz}$ is based on $10^{10}$ cycles and the result of fatigue test on the TC17 titanium alloy is obtained by adopting the up-and-down test method. Based on the result of the test, the fatigue $\mathrm{S}-\mathrm{N}$ curves for the unprocessed, pre-corroded and laser shock-processed specimens are shown in Figure 9. 


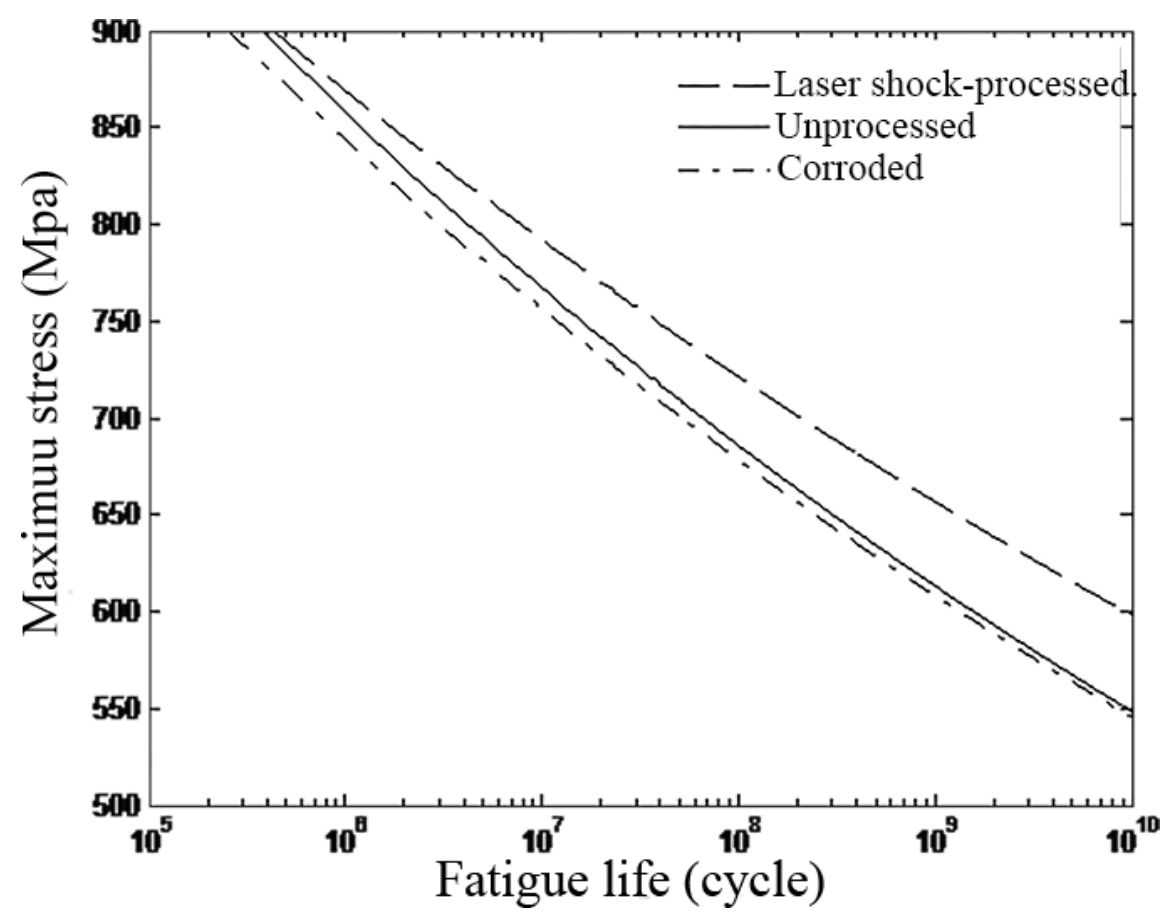

FIGURE 9 The fatigue S-N curves of three groups

It can be seen from the figure that the service life of the three types of TC17 titanium alloy specimens obey lognormal distribution. All the S-N curves show a continuous downward trend, indicating that there is no traditional limit for the very high-cycle fatigue under the condition of symmetrical cyclic stress $(\mathrm{R}=-1)$ and different surface processing has different effects on the very high-cycle fatigue performance of TC17 titanium alloys. After corrosion test, the properties of corroded materials slightly decrease but the degree of reduction is not obvious. Besides, with the increase of loading cycles, their S-N curve becomes closer to that of unprocessed specimens. However, the fatigue performance of materials is greatly improved with laser shock processing and it is obvious in the condition of high cycle number and small load. This indicates that the TC17 titanium alloys have a strong anti-corrosion capability. Their very high-cycle fatigue performance does not decrease significantly under the action of real corrosion environment, and can be improved by the laser shock processing.

Figure 10 shows the location of the fatigue crack of the specimen. It can be seen from the figure that the crack is located at the arc contraction point, the same site as with the maximum stress position in the simulation.

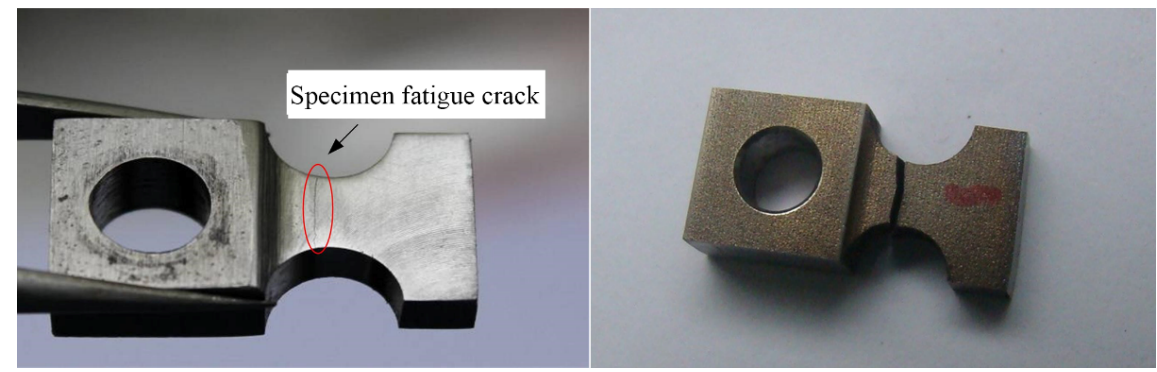

FIGURE 10 Specimen fatigue crack position 


\section{4 | Analysis of Morphological Characteristics}

The crack surface of the fatigue crack specimen have been analyzed by SEM (JSM-5900Lv). The macroscopic and microscopic morphology of the fractures is observed to determine the fatigue crack initiation positions, crack source area and crack propagation morphology. The accelerated voltage of the SEM analysis is $20 \mathrm{kV}$.

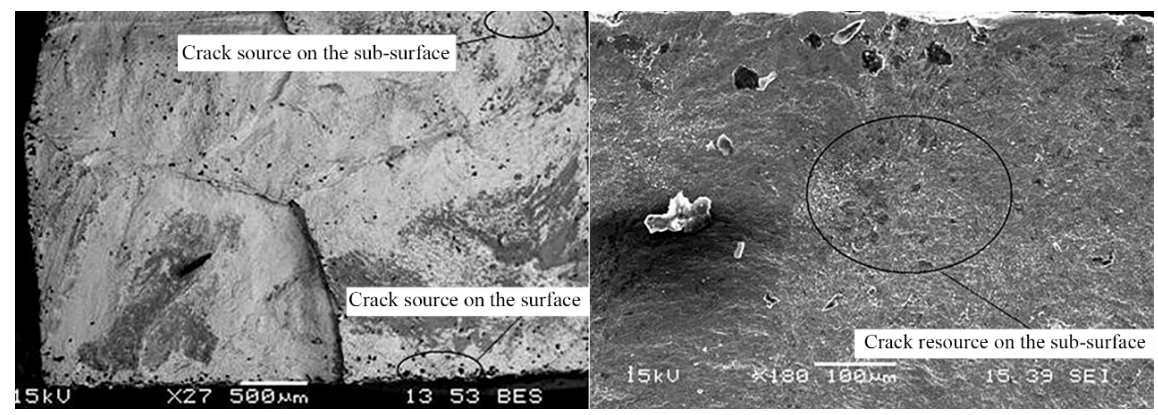

FIGURE 11 (a) The surface and sub-surface crack sources of the unprocessed specimens

Figure 11 shows the fatigue fractures of the crack sources of the specimens of the three processing methods. Among them, Figure 11 (a) shows the fatigue fractures of the unprocessed specimens. It can be seen from the figure, that the unprocessed specimens have crack initiation on both the surfaces and sub-surfaces. The surface cracks generally propagate in a nearly semi-circular manner along the fractures, while the sub-surface cracks generally propagated in a near circular form, that is, the crack shape ratio a/c[?]1, and the fatigue source areas are relatively flat. Radial ridge lines spread from the source areas. This indicates that when the bending vibration occurs, the surface external sides are free and the stress could be released to a certain degree, but the stress of the sub-surfaces could not be released,so, it is sometimes greater than that of the surfaces. Moreover, since the internal strain of bending vibration is relatively small, the stress is small in this way. The crack initiation and propagation start from the place where the stress is large, so the sources of fatigue appear on the sub-surfaces. In addition, the test loading is resonant at ultrahigh-frequency, so the internal temperature of the specimens is very high, the local high temperature of crystals, the uneven plastic strain distribution, and the repeated action of local elasticity and plasticity lead to the fatigue source on the sub-surfaces.

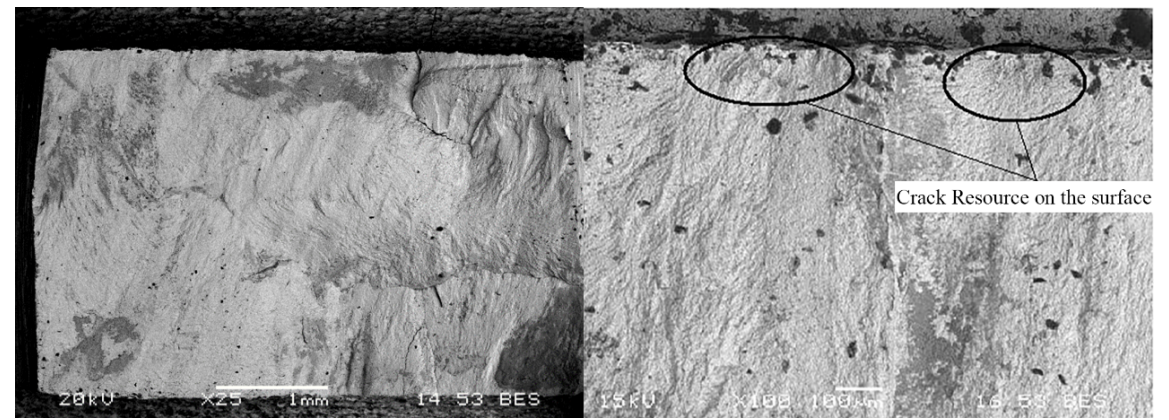

FIGURE 11 (b) The surface crack sources of the corroded specimens

The fatigue fracture surface of the corroded specimens are shown in Figure 11 (b). It can be seen from the figure that the crack initiation only occurs on the surfaces of the corroded specimens and most of the crack initiation on the surface defects or etch pit areas, which is different from the crack initiation positions of the unprocessed specimens. When the surface cracks initiates from the surface defects, the cracks propagate in a nearly semi-circular form, the fatigue source areas are relatively flat, with the radial ridge lines spreading 
from the source areas, accompanied by several crack sources. This is because the specimens are immersed in the corrosive solution, resulting in tiny pitting and etch pits and increasing metal surface roughness. The etch pits and defects on the surface tend to have stress concentration and result in crack sources when the specimens bear bending vibration fatigue load.

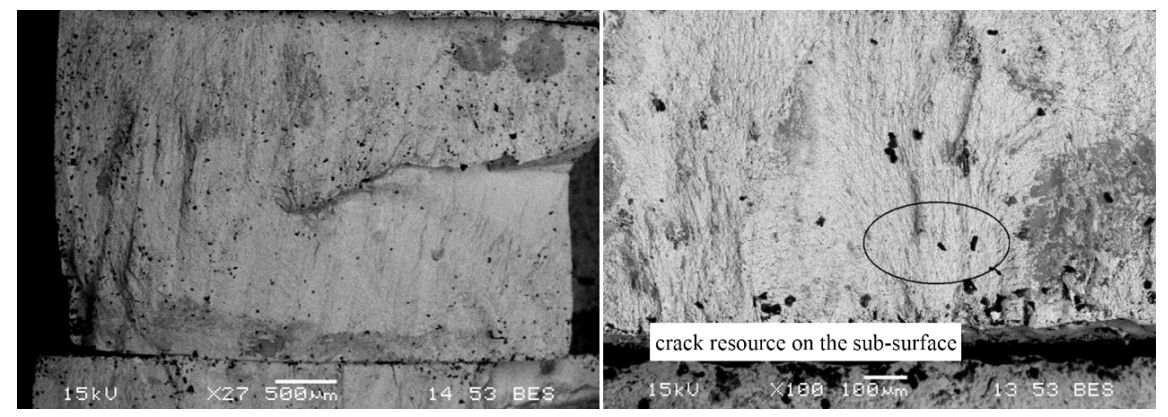

FIGURE 11 (c) The surface and sub-surface crack sources of the laser shock-processed specimens

The fatigue fractures of the laser shock-processed specimens are shown in Figure 11 (c). It can be seen from the figure that the crack initiation only occurs on the sub-surfaces of the laser shock-processed specimens and the cracks propagate in a nearly semi-circular form from the sub-surface defect areas. This is due to the great residual stress and a large number of dislocations generated by grain refinement on the surfaces of the specimen. Therefore, the cracks tend to initiate from the sub-surfaces with higher stress.

In traditional very high-cycle fatigue experiments, the crack source morphology ${ }^{22}$ is characterized by "fisheye" at specimen fracture sub-surface crack initiation positions. Taking as example the internal crack source initiation of very high-cycle rotation bending of high-strength steel, when there are inclusions in the interior, the cracks will sprout at the inclusions and propagate in the form of fish-eye. Israel Marines-Garcia et al. has used alloy steel as an example, dividing "fish-eye" crack source initiation and propagation into three stages, and calculating the theoretical number of cycles required for formation of "fish-eye" 23 .

However, for very high-cycle bending vibration fatigue specimens of TC17 titanium alloys, the morphology of the crack source is not characterized by "fish-eye" at initiation positions of fracture sub-surface crack. This indicates that very high-cycle fatigue crack initiation of TC17 titanium alloys is independent of internal inclusions and defects, which is consistent with the conclusion of the literature references ${ }^{24}$. According to Bathias's ${ }^{25}$ observation, the $\alpha$ phase lath is the internal crack source for titanium alloys. Very high-cycle fatigue cracks can initiate from internal $\alpha_{p}$ grains, $\alpha_{p}$ grain boundaries and $\alpha-\beta$ phase boundaries due to uneven microstructures ${ }^{26,27}$. Therefore, the crack propagation forms vary for different metals and very highcycle bending vibration fatigue crack propagation of TC17 titanium alloys is not characterized as "fish-eye" morphology. It can be seen that whether specimens showing "fish-eye" is related to their material type and the TC17 titanium alloys themselves are not characterized as "fish-eye".

\section{4 | CONCLUSION}

The main failure mode of aero-engine rotor blades is fracture failure caused by bending vibration fatigue. Among all the bending vibrations that cause blade fracture failure, the first-order bending vibration is the most common and of the most harm. A cantilever beam-type very high-cycle bending fatigue test system suitable for simulating very high-cycle fatigue test for aviation engine blades has been designed and developed in this paper in view of the very high-cycle fatigue damage forms of aviation engine blades and based on the traditional symmetrical bending very high-cycle fatigue test system. The designed system is used to perform very high-cycle fatigue test on the following three groups of specimens: unprocessed, corroded and laser shock-processed. The corresponding S-N curves are produced based on the fatigue test data. The following conclusions are obtained from the analysis of the S-N curves and on observing the fatigue fractures. 
(1) By analyzing the crack sources of the fatigue fractures of the unprocessed TC17 titanium alloy specimens based on SEM, it can be seen that the crack initiation not only occurs on the surfaces of the specimens but also on the sub-surfaces, different from that shown in the traditional very high-cycle fatigue test.

(2) The S-N curve of the corroded specimens is beneath that of the unprocessed ones. The fatigue performance of the corroded specimens decreases to a certain extent. The positions of the crack initiation are not shown on the sub-surfaces but on surface defects or etch pit areas. The specimens are immersed in the corrosive solution, resulting into tiny pitting and etch pits, and increasing roughness on the metal surface. The etch pits and defects of the surface tend to have stress concentration and lead to crack sources when the specimens bear bending vibration fatigue load.

(3) The S-N curve of the shock-processed specimens is above that of the unprocessed ones. The fatigue performance of the shock-processed specimens is greatly improved, and the improvement is more obvious along with the decrease of cyclic load. The cracks of such specimens are mostly initiated on the sub-surfaces.

\section{Author Contributions:}

Methodology: Hui Zhang, Xuan Chen, Quantong Li; software, Hui Zhang, Jingsheng Shen; investigation: Zhang Hui, Li Cheng; resources: Xuan Chen; data curation: ChangKai Wang; writing - original draft preparation: Hui Zhang, Wenbin Cui; writing - review and editing: Hui Zhang, Xuan Chen; project administration: Xuan Chen, Li Cheng; funding acquisition, Xuan Chen. All authors have read and agreed to the published version of the manuscript.

Funding : This research was funded by National Natural Science Foundation of China Youth Project (11402302), China Postdoctoral Science Foundation (2016M592923) and Natural Science Basic Research Plan in Shaanxi Province of China (2020JQ-477)

Conflicts of Interest: The authors declare no conflict of interest.

\section{REFERENCE}

1. Bathias C, Paris P. Gigacycle fatigue in mechanical practice. USA: CRC Press; 2004.

2. Tao Chun hu, Xi Nian Sheng, Zhong Pei Dao. Failure examples analysis of aeronautical equipments .CN: National Defense Industry Press; 1998(in Chinese)

3. Bathias C. There is no infinite fatigue life in metallic materials. Fatigue Fract Eng Mater Struct . 1999; 22(7): 559-565.

4. Murakam Y., Nomoto T Ueda T. Factors influencing the mechanism of superlong fatigue failure in steels. Fatigue Fract Eng Mater Struct . 1999; 22(7):581-590.

5. Oguma H. Nakamura T. The effect of microstructure on very high-cycle fatigue properties in $\mathrm{Ti}-6 \mathrm{Al}-$ 4V. Scr Mater. 2010; 63(1):32-34.

6. Jha S K, Szczepanski C J, Golden P J , et al. Characterization of fatigue crack-initiation facets in relation to lifetime variability in Ti-6Al-4V. Int $J$ Fatigue . 2012; 42:p.248-257.

7. Furuya Y. A New Model for Predicting the Gigacycle Fatigue Strength of High-Strength Steels. Mater Sci Eng. A . 2018; 743.

8. Wei Li, Xinxin Xing, Ning Gao, Ping Wang. Subsurface crack nucleation and growth behavior and energy-based life prediction of a titanium alloy in high-cycle and very-high-cycle regimes.Eng Fract Mech. 2019; 221(221).

9. Huang J, Spowart J E, Jones J W. The role of microstructural variability on the very high-cycle fatigue behavior of discontinuously-reinforced aluminum metal matrix composites using ultrasonic fatigue. Int J Fatigue . 2010; 32(8):p.1243-1254.

10. Prokhorov A, Petrova A, Plekhov O. The Study of Evolution of Physical and Mechanical Properties of Metals Under Very High Cycle Fatigue.Procedia Structural Integrity . 2017; 5:555-561.

11. Yoshinaka F, Nakamura T, Nakayama S, et al. Non-destructive observation of internal fatigue crack growth in Ti-6Al-4V by using synchrotron radiation $\mu \mathrm{CT}$ imaging. Int $J$ Fatigue . 2016; 93(pt.2):397405. 
12. Li W, Sun R, Gao N, et al. Interior induced fatigue of surface-strengthened steel under constant and variable loading: Failure mechanism and damage modeling. Fatigue Fract Eng Mater Struct . 2019; 42(10).

13. Stefan Heinz, Frank Balle, Guntram Wagner, Dietmar Eifler. (2013) Analysis of fatigue properties and failure mechanisms of Ti- $6 \mathrm{Al}-4 \mathrm{~V}$ in the very high-cycle fatigue regime using ultrasonic technology and 3D laser scanning vibrometry. Ultrasonics.2013; 53 (8):1433-1440.

14. Oguma H, Nakamura T. The effect of microstructure on very high-cycle fatigue properties in $\mathrm{Ti}-6 \mathrm{Al}-$ 4V. Scr Mater. 2010; 63(1):32-34.

15. Nikitin A, Bathias C, Palin-Luc T. A new piezoelectric fatigue testing machine in pure torsion for ultrasonic gigacycle fatigue tests: application to forged and extruded titanium alloys. Fatigue Fract Eng Mater Struct. 2015; 38(11): 1294-1304.

16. Furuya Y, Nishikawa H, Hirukawa H, Nagashima N, Takeuchi E. Catalogue of nims fatigue data sheets. Sci Technol Adv Mat 2019;20 (1): 1055-1072.

17. Uematsu Y, Kakiuchi T, Hattori K. Ebsd-assisted fractography of sub-surface fatigue crack initiation mechanism in the ultrasonic-shot-peened ßeta-type titanium alloy. Fatigue Fract Eng Mater Struct. 2018; 41(11): 2239-2248.

18. Yan Gui Ling, Wang Hong, Kang Guo Zheng, Dai Jing An. Experimental study on the Very-HighCycle-Fatigue properties of 6065A Aluminum alloy for high-speed train. China Railway Science . 2014; 35(01):67-71.(in Chinese)

19. Bao Xuechun, Cheng Li, Ding Junliang, Chen Xuan, Lu Kaiju, Cui Wenbin. The Effect of Microstructure and Axial Tension on Three-Point Bending Fatigue Behavior of TC4 in High Cycle and Very high-cycle Regimes.Materials , 2019; 13(1).

20. Tang Weiwei, Wang Hong. Method of ultrasonic bending fatigue and application. Mechanics in Engineering . 2008; 30(6): 43 46.(in Chinese)

21. Xu Wei, Zhao Yan Guang, Zhong Bin, Yang Xian Feng, Tao Chun hu. Ultra-high frequency fatigue testing approach and verification of TA11 Ti-alloy based on electrodynamic shaker. Journal of Aeronautical Materials. 2019; 39(04): 86-92.(in Chinese)

22. Wang, Q. Y, Berard, J. Y, Dubarre, A,et al. Gigacycle fatigue of ferrous alloys. Fatigue Fract Eng Mater Struct. 2010; 22(8):667-672.

23. Hong Youshi. Zhao Qianan. Qian Guian. Essential characteristics and influential factors for VeryHigh-Cycle-Fatigue behavior of metallic materials, Acta Metallurgica Sinica. 2009;4(7): 769 780.(in Chinese)

24. Marines-Garcia I, Paris P C, Tada H, et al. Fatigue crack growth from small to large cracks on very high cycle fatigue with fish-eye failures. Eng Fract Mech. 2008; 75(6):1657-1665.

25. Yongde L, Zhenguo Y., Shouxin L., Yangbo, L. Correlations between very high-cycle fatigue properties and inclusions of GCr15 bearing steel. Acta Metallurgica Sinica . 2008; 44(8):968-972.(in Chinese)

26. Zuo J H, Wang Z G, Han E H. Effect of microstructure on ultra-high cycle fatigue behavior of Ti-6Al4V. Mat Sci Eng A-Struct.2008; 473(1-2):p.147-152.

27. Lanning D B, Nicholas T, Haritos G K. Effect of plastic prestrain on high cycle fatigue of Ti-6Al-4V. Mech Mater. 2002; 34(2):127-134. 

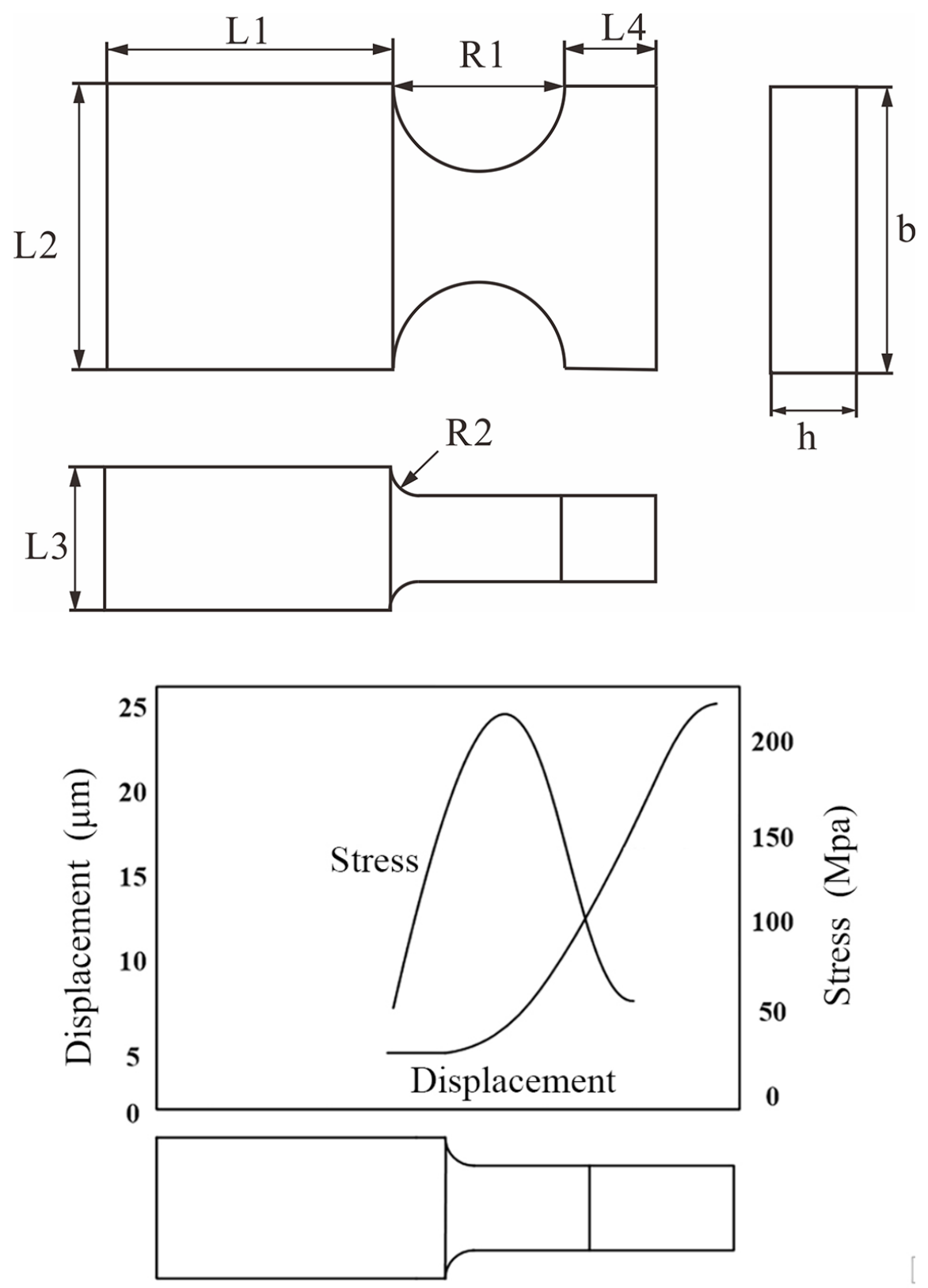

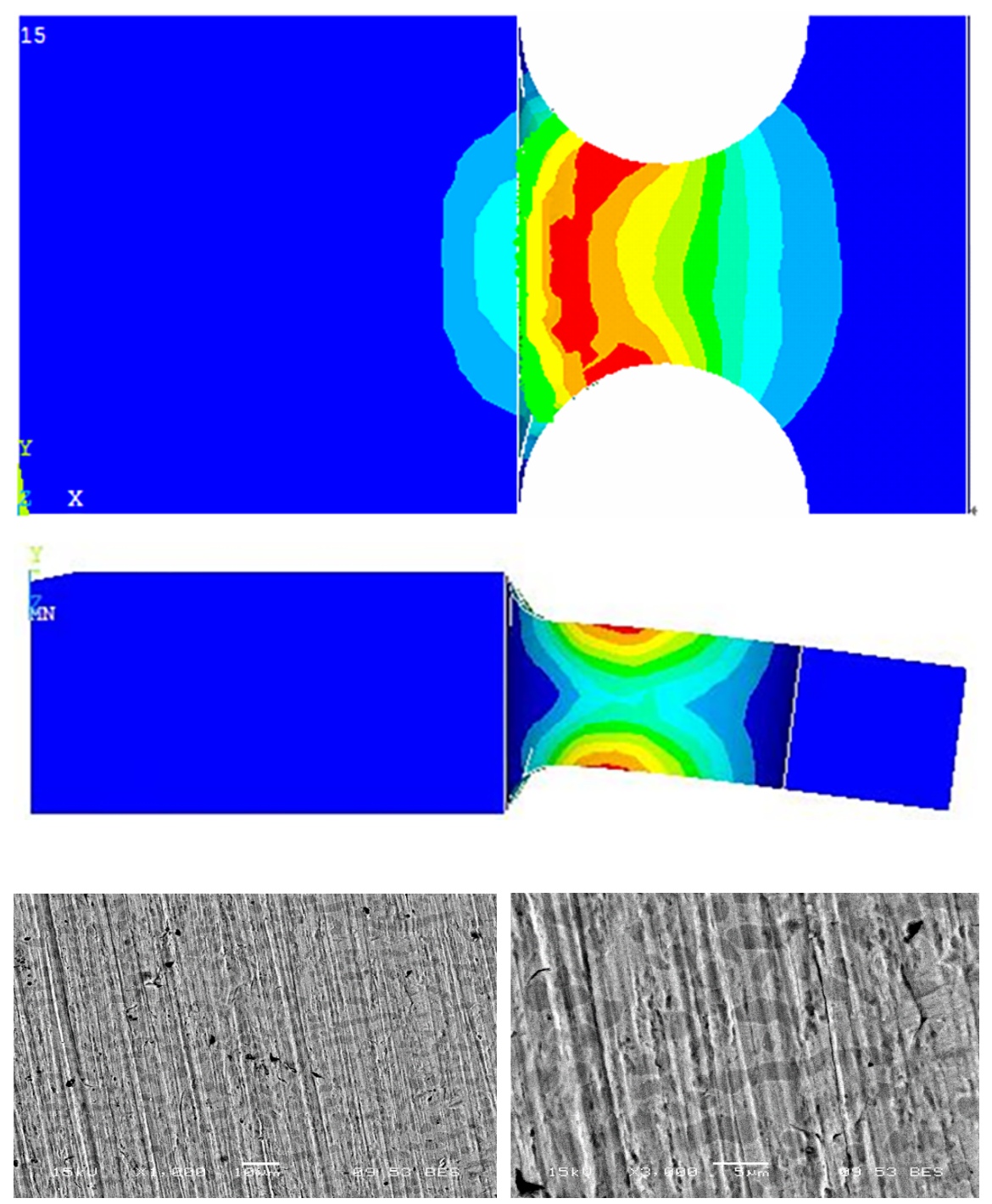


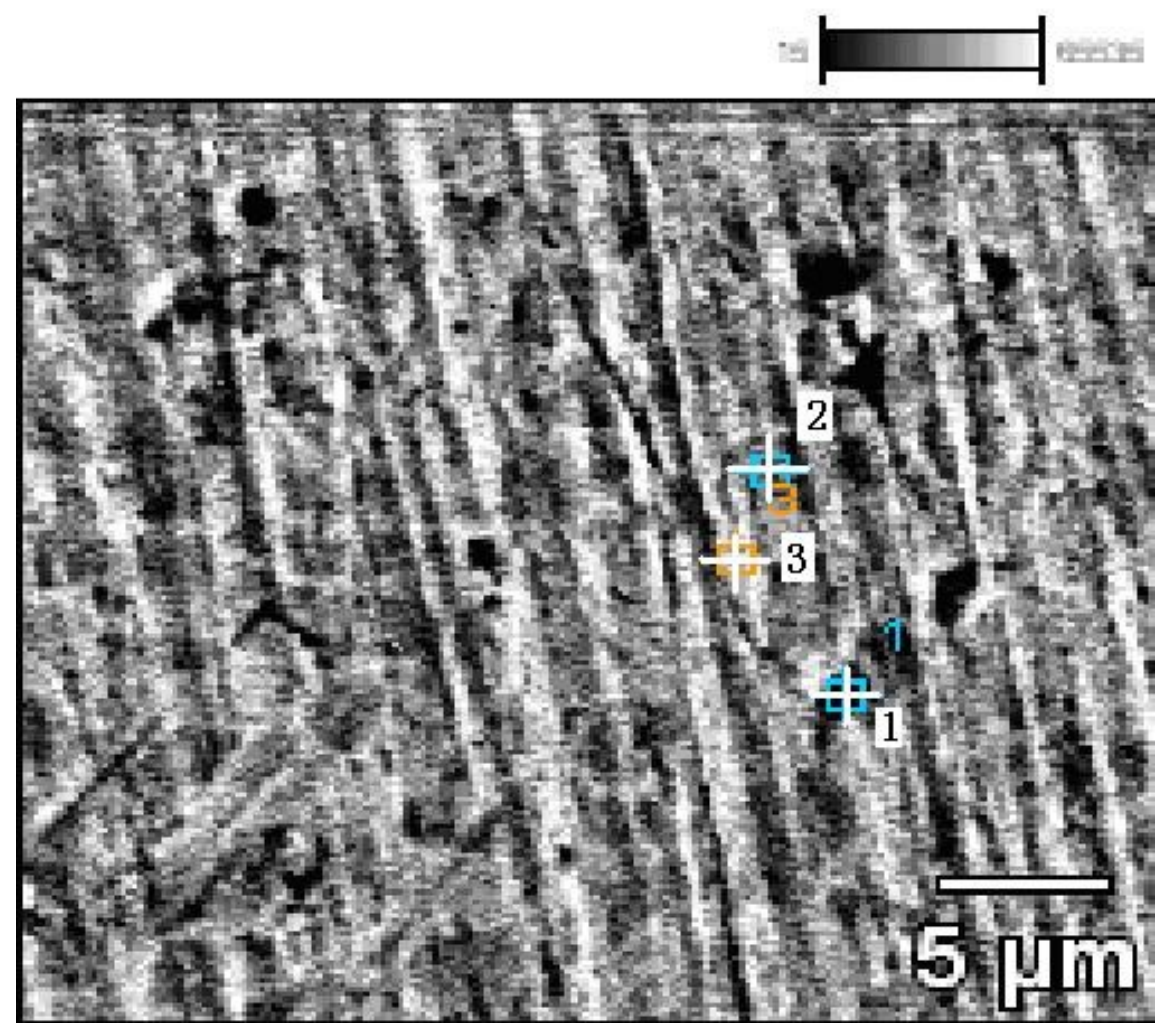


Full scale counts: 563

Base_pt1

(a)

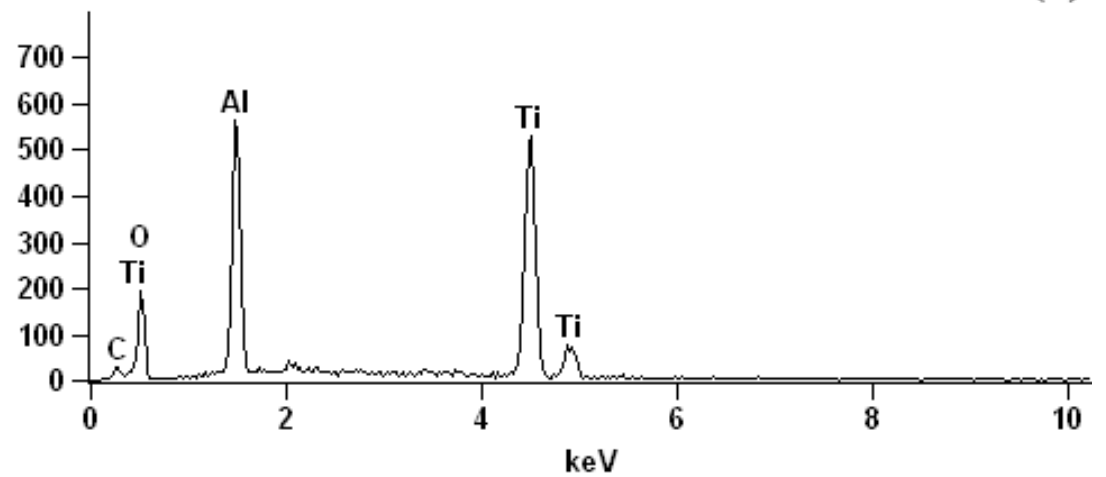

Full scale counts: 787

Base_pt2

(b)

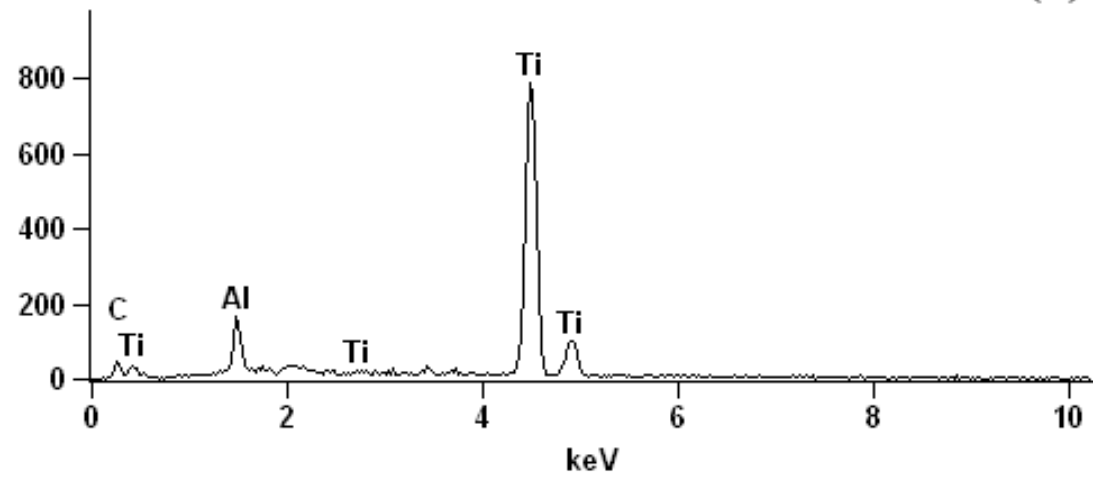

Full scale counts: 743

Base_pt3

(c)
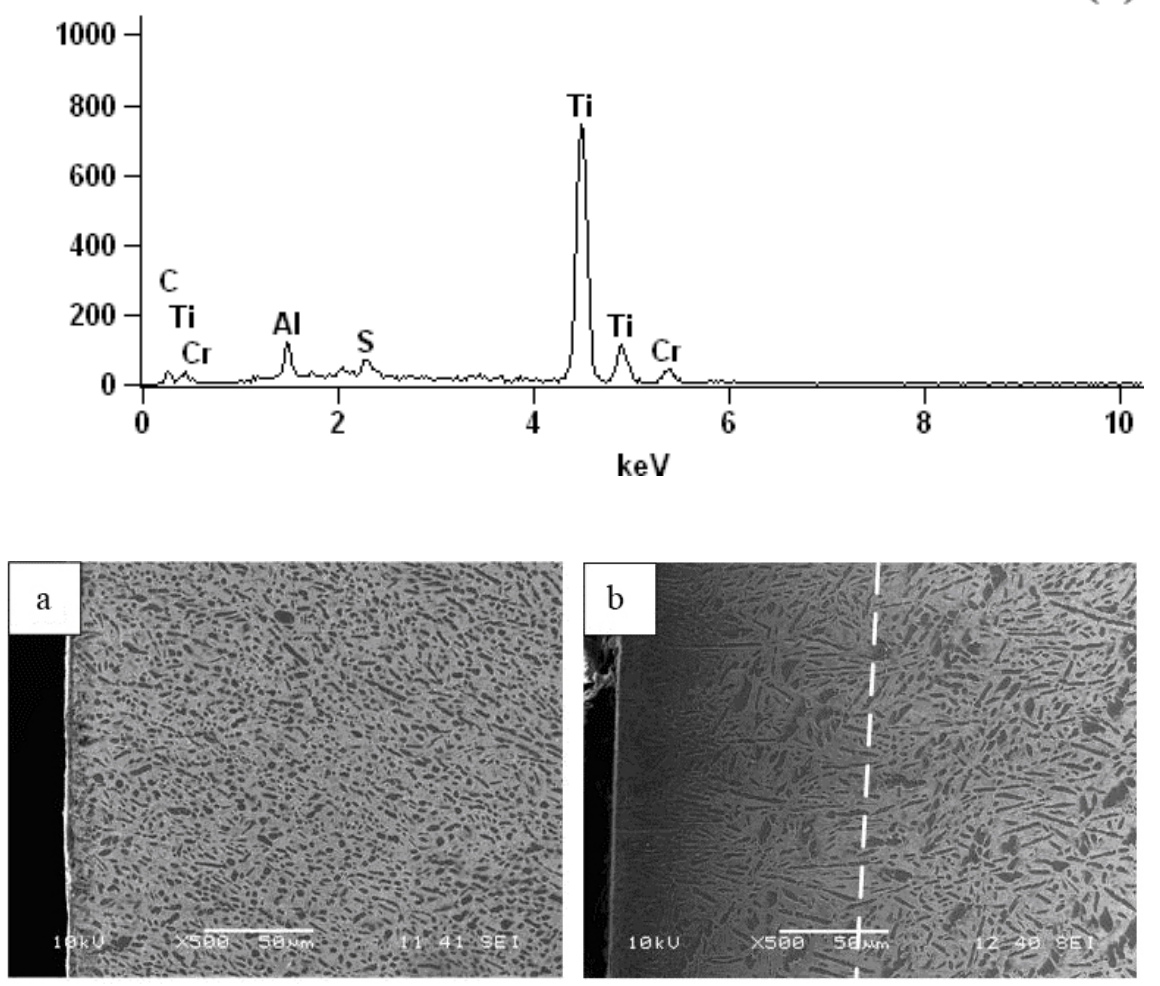

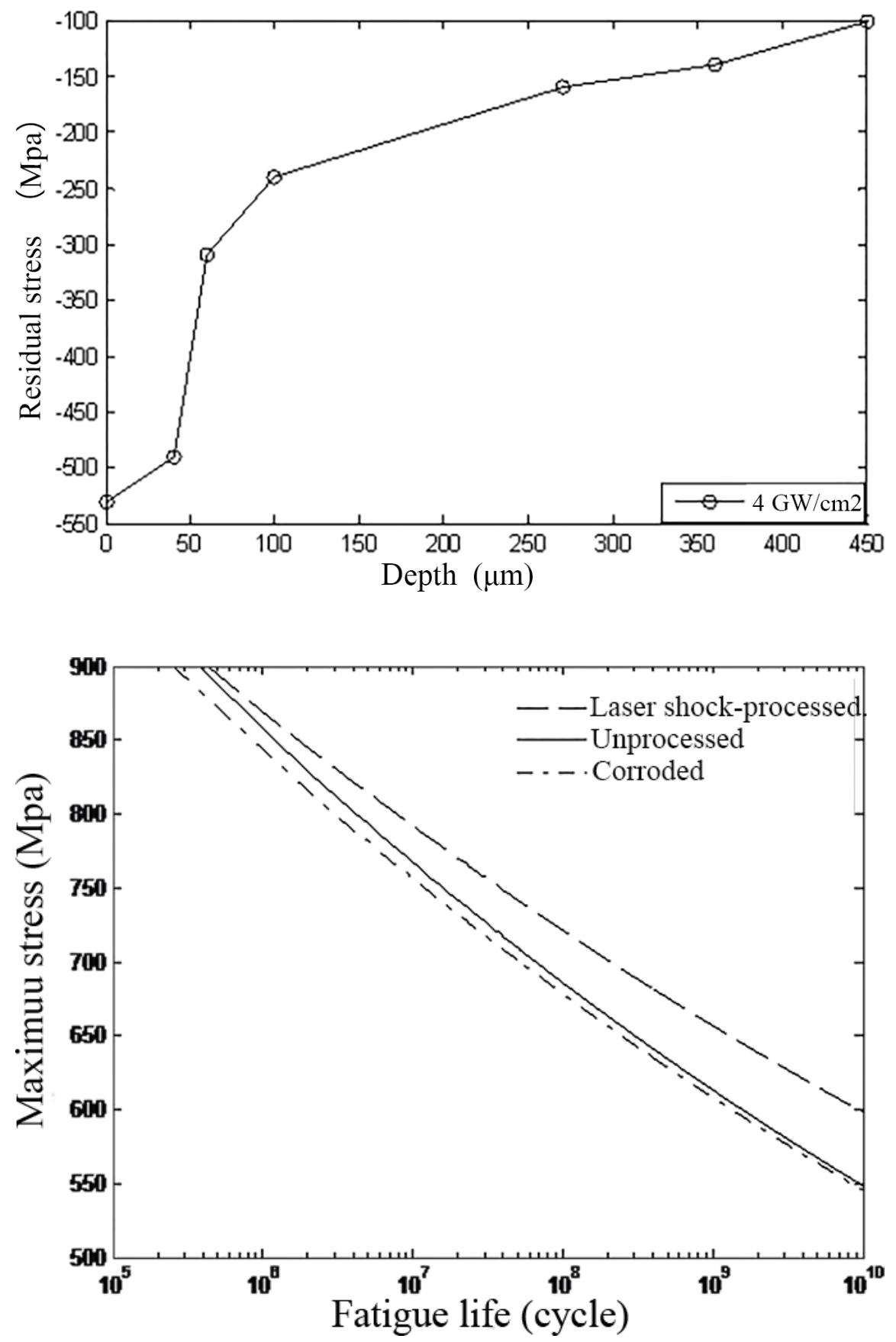

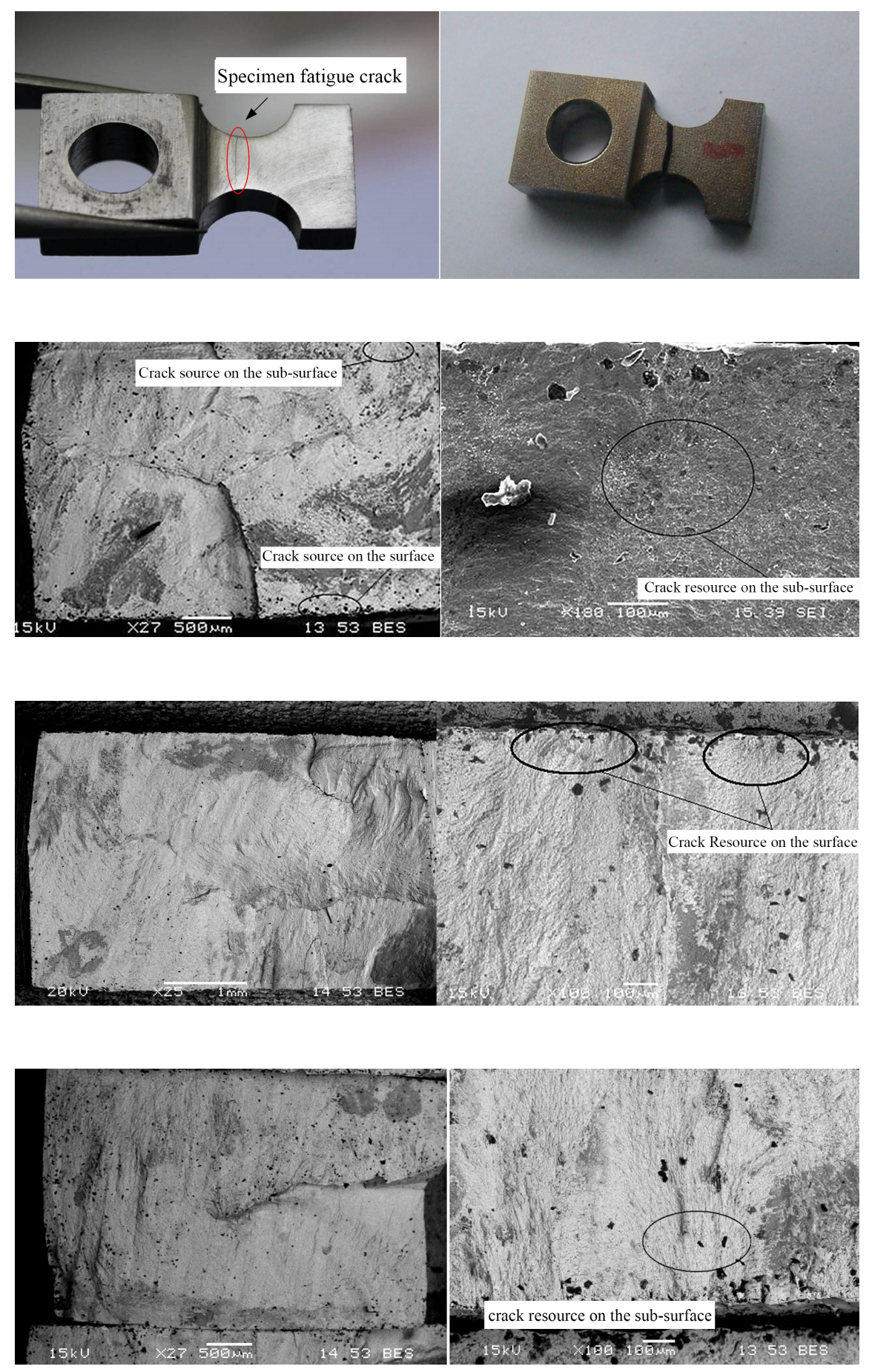

\section{Hosted file}

table1.docx available at https://authorea.com/users/333328/articles/462235-study-onvery-high-cycle-bending-vibration-fatigue-performance-of-tc17-titanium-alloys-undercorrosion-and-laser-shock-processing

\section{Hosted file}


table3.docx available at https://authorea.com/users/333328/articles/462235-study-onvery-high-cycle-bending-vibration-fatigue-performance-of-tc17-titanium-alloys-undercorrosion-and-laser-shock-processing

\section{Hosted file}

table5.docx available at https://authorea.com/users/333328/articles/462235-study-onvery-high-cycle-bending-vibration-fatigue-performance-of-tc17-titanium-alloys-undercorrosion-and-laser-shock-processing 